\title{
Analisis Kinerja Simpang Bersinyal di Simpang Papar Untuk Perencanaan Jalan Tol Kertosono-Kediri
}

\author{
R. Endro Wibisono* ${ }^{1}$, Muhammad Shofwan Donny Cahyono ${ }^{2}$, Adhi Muhtadi ${ }^{3}$ \\ ${ }^{1}$ Fakultas Teknik Universitas Negeri Surabaya \\ ${ }^{2}$ Fakultas Teknik Universitas Widya Kartika \\ ${ }^{3}$ Fakultas Teknik Universitas Narotama \\ e-mail: *1endrowibisono@unesa.ac.id, ̌ㅗhofwandonny@widyakartika.ac.id,

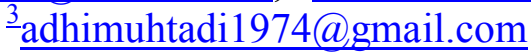

\begin{abstract}
The Papar intersection is a very congested route because the location is in the Kertosono-Kediri toll road planning area for the economic distribution of the Western and Southern East Java Provinces. There needs to be a traffic engineering management so that the intersection is not increasingly saturated. As a benchmark is the forecasting of traffic performance carried out for 2 years from 2019 to 2021. The intersection of the Simpang Papar due to the construction of the Kertosono-Kediri toll road will decrease the value of the DS by developing the Kertosono-Kediri toll road so that the DS value is below 1 (one). The lowest 2021 DS is 0.17, while the highest DS is 0.46. Based on the results of forecasting, the intersection of Papar after the construction of the Kertosono - Kediri toll road has increased the volume of traffic along with the growth in vehicle numbers. The lowest 2045 DS year is 0.94, while the highest DS is 2.51. The solution to dealing with traffic congestion in the year 2045 is by traffic monitoring, especially the signal settings and vehicle restrictions.
\end{abstract}

Keywords - traffic performance, degree of saturation, signal intersection, toll planning

\begin{abstract}
Abstrak
Simpang Papar merupakan jalur yang sangat padat karena lokasinya berada pada area perencanaan tol Kertosono-Kediri untuk distribusi perekonomian wilayah Propinsi Jawa Timur Bagian Barat dan bagian selatan. Perlu adanya manajemen rekayasa lalu lintas supaya simpang tersebut tidak semakin jenuh. Sebagai tolok ukur adalah Peramalan kinerja lalu lintas dilakukan selama 2 tahun dari tahun 2019 hingga tahun 2021. Simpang bersinyal Simpang Papar akibat pembangunan jalan tol Kertosono-Kediri akan menurun nilai DS nya dengan dilakukan rencana pembangunan jalan tol Kertosono - Kediri sehingga pada nilai DS dibawah 1 (satu). Tahun 2021 DS terendah adalah 0,17, Sedangkan DS tertinggi 0,46. Berdasarkan hasil perhitungan peramalan, simpang Papar setelah dilakukan pembangunan jalan tol Kertosono - Kediri mengalami peningkatan volume lalu-lintas seiring pertumbuhan angka kendaraan. Tahun 2045 DS terendah adalah 0,94, Sedangkan DS tertinggi 2,51. Solusi untuk menangani kepadatan lalu-lintas pada tahun 2045 tersebut adalah dengan rekaysa lalu-lintas terutama pengaturan sinyal dan pembatasan kendaraan.
\end{abstract}

Kata kunci-kinerja lalu-lintas, derajat kejenuhan, simpang bersinyal, perencanaan tol 


\section{PENDAHULUAN}

Simpang Papar adalah salah satu simpang yang terletak di Kabupaten Kediri. Kondisi simpang yang sampai saat ini sangat padat menimbulkan kemacetan pada waktu jam puncak pagi dan jam puncak sore. Permasalahan lain adanya perlintasan kereta api, tempat menaikkan dan menurunkan penumpang angkutan umum serta kawasan pardagangan pusat oleh - oleh akan menimbulkan permasalahan kinerja simpang.

Kawasan perdagangan dan tempat pemberhentian angkutan umum yang terjadi parkir sembarangan di sekitar persimpangan ini yang terjadi dengan adanya pelanggaran rambu lalu lintas sehingga dapat mempengaruhi kinerja simpang kondisi eksiting dan menimbulkan kemacetan. Kemacetan yang di akibatkan arus volume lalu lintas yang cukup padat serta antrian di persimpangan cukup panjang. Sehingga perlu evaluasi kinerja pada simpang Papar yang lebih optimal dan alternatif solusi manajemen rekayasa lalu lintas.

Rencana dari pihak pemerintah adalah berupaya pembangunan jalan tol Kertosono Kediri akan tetapi sebelumnya perlu diperhitungkan kinerja simpang tak bersinyal. Maka diperlukan survei volume lalu lintas dan pertumbuhan kendaraan dari tahun ke tahun agar mengetahui berapa pertumbuhan lalu lintas setiap tahunnya sehingga mengakibatkan kemacetan.

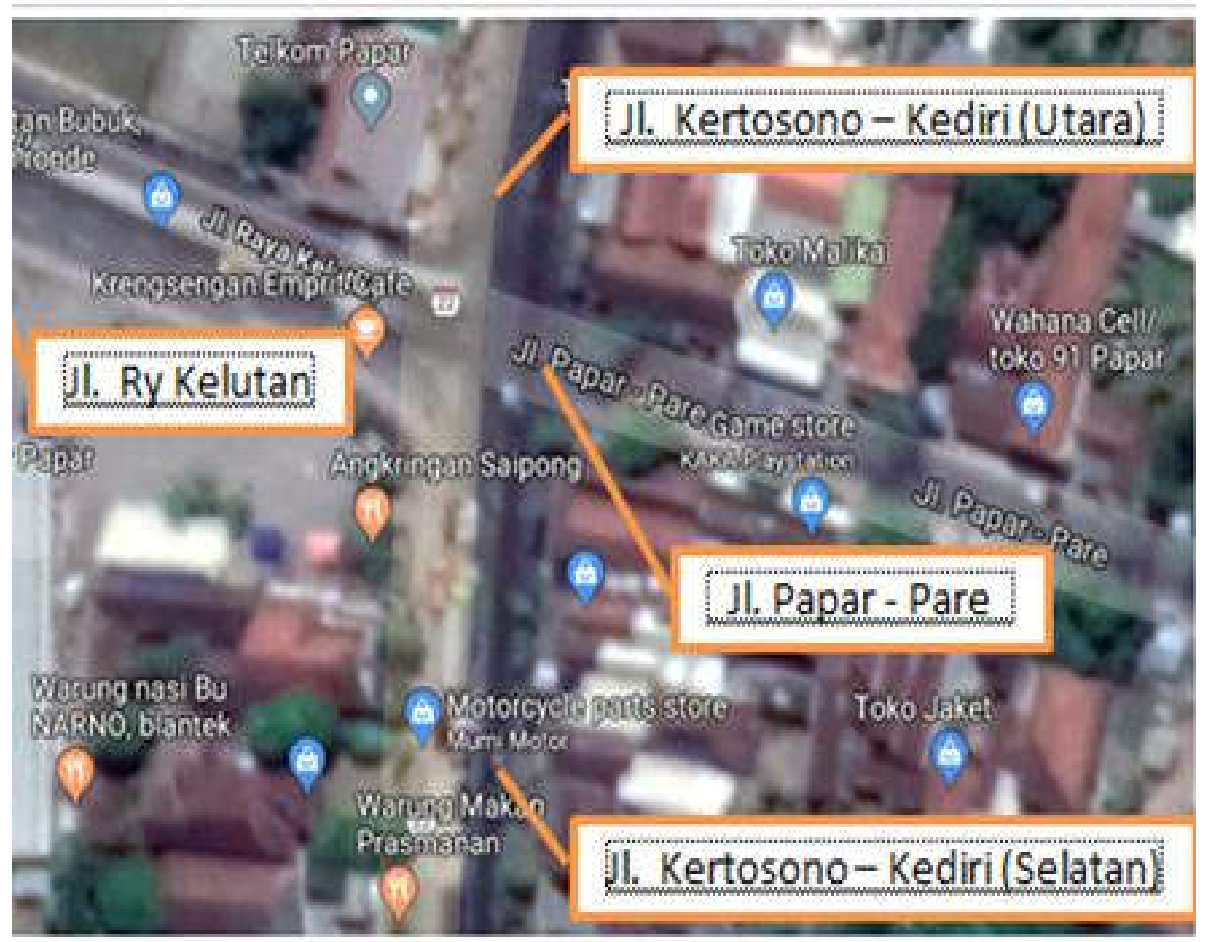

Gambar 1 Empat Pendekat Simpang Papar

\section{METODE PENELITIAN}

Data primer mengenai kondisi lalu lintas jaringan jalan di sekitar lokasi didapatkan 
dengan melakukan pencacahan lalu lintas kendaraan yang lewat. Survei dilaksanakan selama 3 hari (dipilih yang mewakili hari kerja dan libur) untuk kedua jurusan; masing-masing selama 18 jam. Untuk masing-masing lokasi, survei dilakukan selama 3 (tiga) hari selama 18 jam yang dibagi dalam 2 shift survei, masing-masing 6 jam. Pembagiannya antara lain, shift ke 1, Jam $06.00 \mathrm{sd} 12.00$, shift ke $2:$ Jam $12.00 \mathrm{sd}$

18.00, shift ke 3 : Jam 18.00 sd 24.00 .

Survey dilaksanakan pada hari kerja. Adapun perlatan yang dibutuhkan untuk melakukan survey traffic counting adalah dengan menggunakan counter, jam tangan dan peralatan tulis. Data sekunder adalah data yang diperoleh secara tidak langsung dari instnasi terkait. Data sekunder yang dibutuhkan untuk mendukung studi ini antara lain:

Pengumpulan data di peroleh dari hasil survei langsung dilapangan dan dari instansi terkait. Pengumpulan data tersebut digolongkan menjadi dua yaitu data primer dan data sekunder. Salah satu cara pengendalian persimpangan adalah dengan alat pemberi isyarat lalu lintas atau sinyal lampu lalu lintas (SLLL). (Wibisono, 2019).

Berdasarkan data-data yang diperoleh, dapat dilakukan perhitungan arus lalu lintas (Q), kapasitas (Ci), derajat kejenuhan (DJ), panjang antrian (PA), tundaan (T), maupun faktor prilaku yang berpengaruh terhadap kondisi lalu lintas persimpangan apakah dapat dipertahankan. Selanjutnya mengevaluasi kinerja simpang dengan melakukan; Rekapitulasi data, Mengevaluasi waktu sinyal traffic light, Mengevaluasi pengaturan fase lalu lintas, Mengevaluasi kondisi geometri jalan, Analisis kinerja lalu lintas, Teknik analisis data, Kesimpulan dan saran.

\section{HASIL DAN PEMBAHASAN}

Data arus lalu lintas yang digunakan dalam studi ini diperoleh dari survei primer pada 4 lokasi (ruas jalan) yang berlokasi di sekitar rencana pengembangan ruas tol Kediri-Kertosono. Grafik fluktuasi pergerakan volume lalu lintas dalam satuan mobil penumpang per jam (smp/jam) pada Simpang Papar yang terbagi menjadi tiga arah dapat dilihat pada gambar 2.

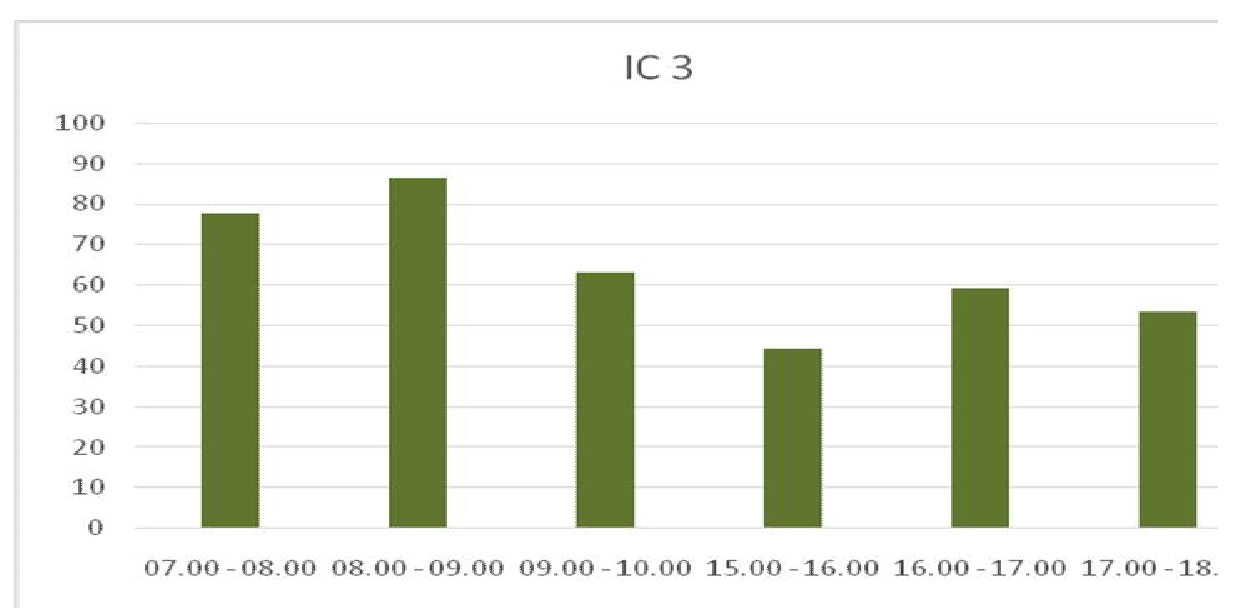

Gambar 2 Grafik. fluktuasi lalu-lintas di Simpang Papar Arah Kediri-Kertosono 
Berdasarkan gambar diatas dapat dianalisa sebagai berikut, Arah Nganjuk ke Kediri. Total volume pada jam puncak (Peak Hour) terjadi pada pagi hari yaitu sekitar jam 07.00 08.00 sebesar $65 \mathrm{smp} / \mathrm{jam}$.

Arah Nganjuk ke Kertosono. Total volume pada jam puncak (Peak Hour) terjadi pada sore hari yaitu sekitar jam 16.00 - 17.00 sebesar 52 smp/jam. Arah Nganjuk ke Pare. Total volume pada jam puncak (Peak Hour) terjadi pada sore hari yaitu sekitar jam $16.00-17.00$ sebesar $265 \mathrm{smp} / \mathrm{jam}$.

Arah Kediri ke Kertosono. Total volume pada jam puncak (Peak Hour) terjadi pada sore hari yaitu sekitar jam 17.00 - 18.00 sebesar 347 smp/jam. Arah Kediri ke Pare. Total volume pada jam puncak (Peak Hour) terjadi pada pagi hari yaitu sekitar jam $09.00-10.00$ sebesar 103 smp/jam.Arah Kediri ke Nganjuk. Total volume pada jam puncak (Peak Hour) terjadi pada pagi hari yaitu sekitar jam $09.00-10.00$ sebesar $104 \mathrm{smp} / \mathrm{jam}$.

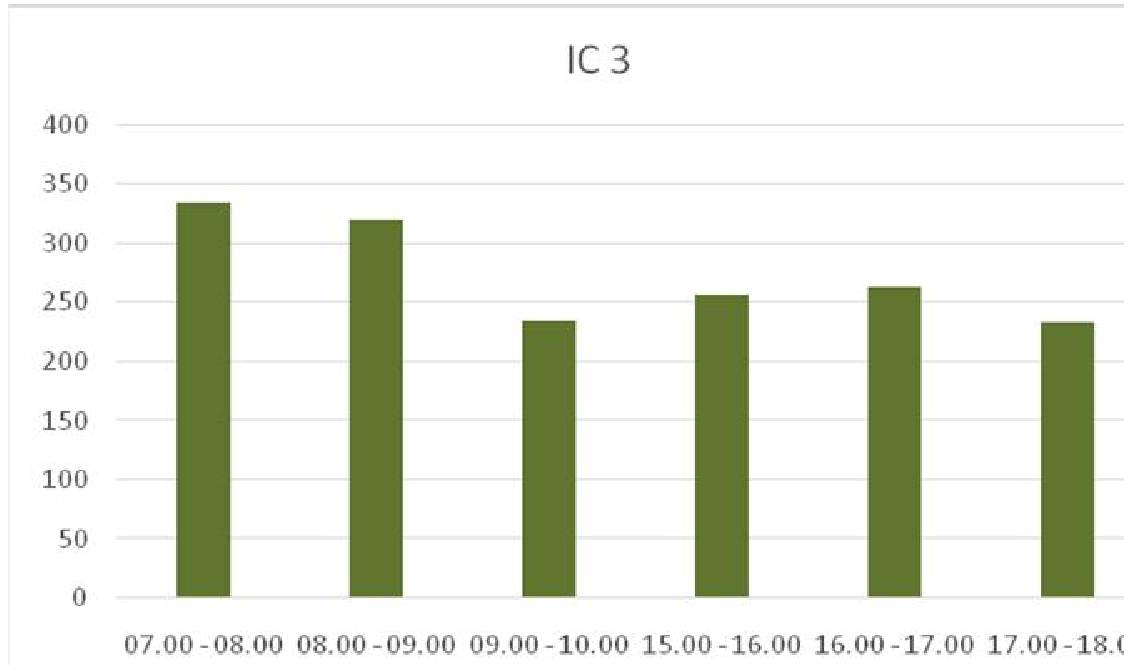

Gambar 3 Grafik. fluktuasi lalu-lintas di Simpang Papar Arah Kertosono-Kediri

Arah Kertosono ke Kediri. Total volume pada jam puncak (Peak Hour) terjadi pada pagi hari yaitu sekitar jam 07.00 - 08.00 sebesar 334 smp/jam. Arah Kertosono ke Pare. Total volume pada jam puncak (Peak Hour) terjadi pada pagi hari yaitu sekitar jam $08.00-09.00$ sebesar $126 \mathrm{smp} / \mathrm{jam}$. Arah Kertosono ke Nganjuk. Total volume pada jam puncak (Peak Hour) terjadi pada pagi hari yaitu sekitar jam 08.00 - 09.00 sebesar $65 \mathrm{smp} / \mathrm{jam}$.

Arah Pare ke Kediri. Total volume pada jam puncak (Peak Hour) terjadi pada pagi hari yaitu sekitar jam 09.00 - 10.00 sebesar 65 smp/jam. Arah Pare ke Kertosono. Total volume pada jam puncak (Peak Hour) terjadi pada pagi hari yaitu sekitar jam 08.00 - 09.00 sebesar $86 \mathrm{smp} / \mathrm{jam}$. Arah Pare ke Nganjuk. Total volume pada jam puncak (Peak Hour) terjadi pada sore hari yaitu sekitar jam 16.00 - 17.00 sebesar 614 smp/jam.

Pada Simpang Papar volume lalu-lintas saat jam puncak (Peak Hour) yaitu pada pukul 07.30 - 08.30 sebesar $1593 \mathrm{smp} / \mathrm{jam}$. Untuk uraian lebih lengkapnya dapat dilihat pada tabel 1 berikut ini: 
Tabel1 VolumeLalu-lintasSimpangPapar

\begin{tabular}{ccc}
\hline Waktu & Total22/08/2017(smp) & Total23/08/2017(smp) \\
\hline $07.00-08.00$ & 1004 & 1530 \\
$07.15-08.15$ & 1079 & 1548 \\
$07.30-08.30$ & 1113 & 1593 \\
$07.45-08.45$ & 1158 & 1512 \\
$08.00-09.00$ & 1213 & 1434 \\
$08.15-09.15$ & 1261 & 1363 \\
$08.30-09.30$ & 1236 & 1279 \\
$08.45-09.45$ & 1179 & 1294 \\
$09.00-10.00$ & 859 & 1337 \\
$15.00-16.00$ & 1375 & 1266 \\
$16.00-17.00$ & 1501 & 1383 \\
$17.00-18.00$ & 1277 & 1328 \\
\hline
\end{tabular}

Sumber: Hasil Perhitungan 2019

Berdasarkan Tabel 1 dilakukan survey dua hari sehingga menghasilkan perbandingan yang terlihat pada grafik gambar 4 berikut ini.

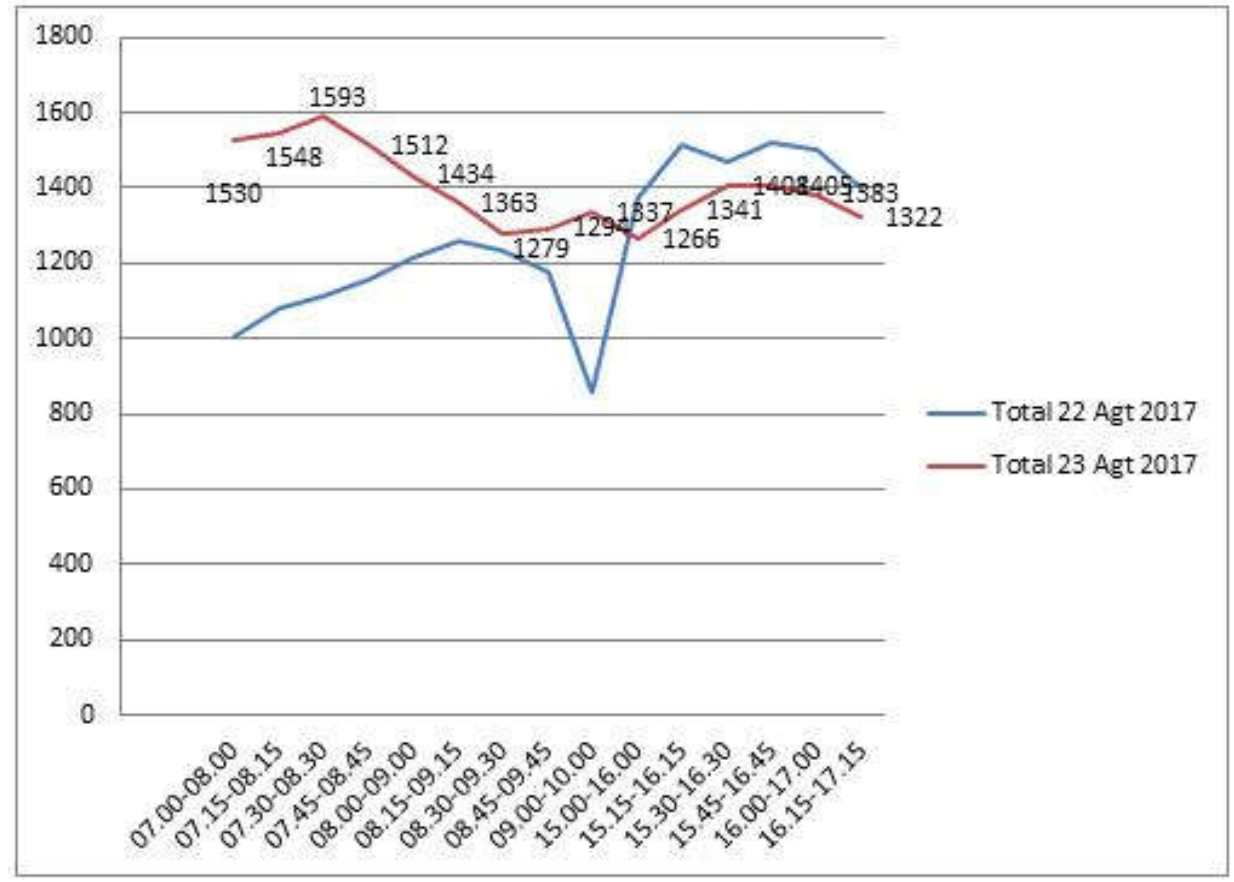

Gambar 4 Grafik. jumlah lalu-lintas di Simpang Papar

Berdasarkan perhitungan jumlah kendaraan di Simpang Papar, peramalan arus lalu lintas digunakan data pertumbuhan kendaraan yang diambil berdasarkan data dari Badan Pusat Statistik (BPS) Kabupaten Kediri Dalam Angka seperti pada Tabel 2 berikut. 
Tabel2PertumbuhanKendaaraanLV,HV,dan MC,KabupatenKediri

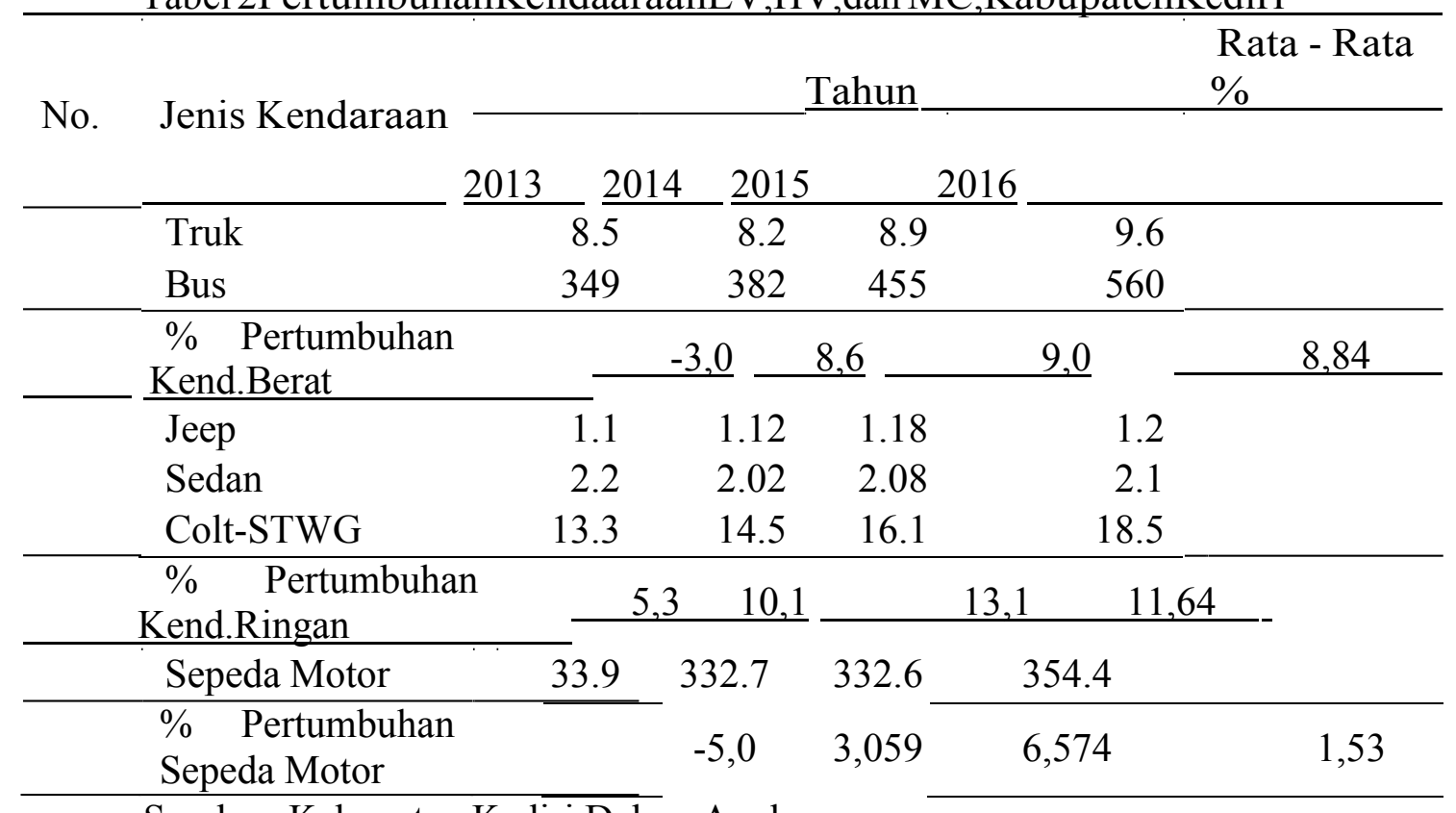

Sumber: Kabupaten Kediri Dalam Angka

Pada Tabel 2 merupakan penjelasan dari parameter-parameter kinerja Simpang Papar pada Tahun 2017 dan prediksi berdasarkan pertumbuhan kendaraan pada Tahun 2021. Hasil perhitungan kinerja Simpang Papar dihitung berdasarkan DS Pada tahun 2017 ke tahun 2021 nilai DS meningkat diakibatkan pertumbuhan arus lalu-lintas kendaraan Untuk lebih jelasnya kinerja Simpang Papar disampaikan pada Tabel 3 berikut.

Tabel 3 Kinerja Lalu-lintas Simpang Papar Berdasarkan Pertumbuhan

KendaraandiKabupatenKediri Tahun2021

\begin{tabular}{cllll}
\hline Kode Pendekat & $\begin{array}{l}\text { Arus Lalu-lintas } \\
(\text { Smp/jam) }\end{array}$ & $\begin{array}{l}\text { Kapasitas } \\
(\text { Smp/jam })\end{array}$ & $\begin{array}{l}\text { Derajat } \\
\text { Jenuh }\end{array}$ & $\begin{array}{l}\text { Panjang } \\
\text { antrian } \\
\text { (meter) }\end{array}$ \\
\hline $\mathrm{U}$ & 450 & 980 & 0,46 & 108,6 \\
\hline $\mathrm{S}$ & 173 & 1010 & 0,17 & 34,3 \\
\hline $\mathrm{T}$ & 140 & 636 & 0,22 & 146,7 \\
\hline $\mathrm{B}$ & 294 & 888 & 0,33 & 62,9 \\
\hline
\end{tabular}

Sumber: Hasil Perthitungan (2019)

Berdasarkan hasil perhitungan peramalan, simpang Papar akan menurun nilai DS nya dengan dilakukan rencana pembangunan jalan tol Kertosono - Kediri sehingga pada nilai DS dibawah 1 (satu). Tahun 2021 DS terendah adalah 0,17, Sedangkan DS tertinggi 0,46.

Peramalan kinerja lalu lintas berfungsi untuk memperbaiki dan memperlancar kembali arus lalu lintas yang stabil dan tidak terjadi kemacetan. Peramalan dilakukan pada tahun 20145. Arus lalu lintas dan nilai DS tahun 2021 dapat dilihat pada tabel 4 berikut. 
Tabel 4 Kinerja Lalu-lintas Simpang Papar Berdasarkan Pertumbuhan KendaraandiKabupatenKediri Tahun2045

\begin{tabular}{rllll}
\hline $\begin{array}{l}\text { Kode } \\
\text { Pendekat }\end{array}$ & $\begin{array}{l}\text { Arus Lalu-lintas } \\
\text { (Smp/jam) }\end{array}$ & $\begin{array}{l}\text { Kapasitas } \\
\text { (Smp/jam) }\end{array}$ & $\begin{array}{l}\text { Derajat } \\
\text { Jenuh }\end{array}$ & $\begin{array}{l}\text { Panjang } \\
\text { antrian } \\
\text { (meter) }\end{array}$ \\
\hline $\mathrm{U}$ & 2462 & 980 & 2,51 & 342,9 \\
\hline $\mathrm{S}$ & 946 & 1010 & 0,94 & 114,3 \\
\hline $\mathrm{T}$ & 769 & 636 & 1,21 & 116,7 \\
\hline $\mathrm{B}$ & 1609 & 888 & 1,81 & 214,3 \\
\hline
\end{tabular}

Sumber: Hasil Perthitungan (2019)

Berdasarkan hasil perhitungan peramalan, simpang Papar setelah dilakukan pembangunan jalan tol Kertosono - Kediri mengalami peningkatan volume lalu-lintas seiring pertumbuhan angka kendaraan. Tahun 2045 DS terendah adalah 0,94, Sedangkan DS tertinggi 2,51. Berdasarkan tabel diatas arus lalu lintas simpang bypass krian memiliki tingkat pelayanan tipe $\mathrm{F}$ yakni nilai DS $>1$ sehingga menyebabkan kemacetan, antrian yang panjang dan kecepatan laju kendaraan kadang-kadang nol.

\section{KESIMPULAN}

Berdasarkan penjelasan yang sudah diuraikan, maka ada beberapa kesimpulan yang didapat untuk kinerja simpang bersinyal Simpang Papar akibat pembangunan jalan tol Kertosono-Kediri, antara lain:

Simpang Papar akan menurun nilai DS nya dengan dilakukan rencana pembangunan jalan tol Kertosono - Kediri sehingga pada nilai DS dibawah 1 (satu). Tahun 2021 DS terendah adalah 0,17, Sedangkan DS tertinggi 0,46 .

Berdasarkan hasil perhitungan peramalan, simpang Papar setelah dilakukan pembangunan jalan tol Kertosono - Kediri mengalami peningkatan volume lalu-lintas seiring pertumbuhan angka kendaraan. Tahun 2045 DS terendah adalah 0,94, Sedangkan DS tertinggi 2,51 .

Solusi untuk menangani kepadatan lalu-lintas pada tahun 2045 tersebut adalah dengan rekaysa lalu-lintas terutama pengaturan sinyal dan pembatasan kendaraan. 


\section{DAFTAR PUSTAKA}

[1] April Gunarto, A. I. C. K. (2019). Penelitian Campuran Aspal Beton Dengan Menggunakan Filler Bunga Pinus. UKaRsT, 3(1), 37. https://doi.org/10.30737/ukarst.v3i1.351

[2] Badan Pusat Statistik (2016). Kabupaten Kediri Dalam Angka. Badan Pusat Statistik Kabupaten Kediri. Kediri.

[3] Candra, A I, Mudjanarko, S. W., \& Limantara, A. D. (2017). Manajemen Data Lalu Lintas Kendaraan Berbasis Sistem Internet Cerdas Kadiri. Semnastek, 4(2), 1-2. Retrieved from jurnal.umj.ac.id/index.php/semnastek

[4] Candra, Agata Iwan. (2018). STUDI KASUS STABILITAS STRUKTUR TANAH LEMPUNG PADA JALAN TOTOK KEROT KEDIRI MENGGUNAKAN LIMBAH KERTAS. UKaRsT, 2(2), 11.

[5] Direktorat Jenderal Bina Marga, 1997. Manual Kapasitas Jalan Indonesia. Jakarta: Badan Penerbit Pekerjaan Umum.

[6] Direktorat Jendral Bina Marga (2014). Pedoman Kapasitas Jalan Indonseia (PKJI). Jakarta.

[7] McShane, William R. \& Roess, Roger P. (1990). Traffic Engineering. Pearson Higher Education, Inc. New Jersey.

[8] Miro, Fidel (2004). Perencanaan Transportasi Untuk Perencana dan Praktisi. Erlangga.

[9] Jakarta. Oglesby, Clarkson H dan Hicks. R. G, 1998, “Teknik Jalan Raya“, Jakarta: Erlangga.

[10] Wibisono, RE., Muhtadi, A., \& Cahyono MSD., (2019). "Kajian Analisis Lalulintas Simpang Bersinyal di By Pass Krian Untuk Perencanaan Pelebaran Jalan dan Fly Over". Ge- STRAM: Jurnal Perencanaan dan Rekayasa Sipil, Vol.02, No.01, Maret 2019, hal : 9-15.

[11] Pradipta, R. E., Purba, T., Wicaksono, Y. W. Y., \& k Idriastuti, A. (2017). Evaluasi Kinerja Simpang Bersinyal Dan Flyover Di Bundaran Kalibanteng. Jurnal Karya Teknik Sipil, 6(1), 263-274.

[12] Budi, S., Sihite, G., Indriastuti, A. K., \& Priyono, E. Y. (2017). PERBANDINGAN KINERJA SIMPANG BERSINYAL BERDASARKAN PKJI 2014 DAN PENGAMATAN LANGSUNG (Studi Kasus: Simpang Jl. Brigjend Sudiarto/Jl. Gajah Raya/Jl. Lamper Tengah Kota Semarang. Jurnal Karya Teknik Sipil, 6(2), 180-193.

[13] Khairunnisa, N. F., Yanti, A., Priyono, E. E. Y., \& Supriyono, S. (2017). Evaluasi Kinerja Lalu Lintas Simpang Di Jalan Layang Dan Bundaran Kalibanteng, Semarang Dengan Nilai Ekuivalensi Mobil Penumpang Simpang Bersinyal Terkoreksi. JURNAL KARYA TEKNIK SIPIL, 6(2), 107-117.

[14] Sraun, D., Rumayar, A. L., \& Longdong, J. (2018). ANALISA KINERJA LALU LINTAS PERSIMPANGAN LENGAN TIGA BERSIGNAL DI MANADO (Studi Kasus: Persimpangan Jalan RE Martadinata). JURNAL SIPIL STATIK, 6(7).

[15] Kristanto, H. S. (2013). Evaluasi Kinerja Simpang Bersinyal (Studi Kasus Simpang Bangak di Kabupaten Boyolali) (Doctoral dissertation, Universitas Muhammadiyah Surakarta). 